Interaction Latin America

Rio de Janeiro, Brasil - 2018

http://ila.ixda.org/2018

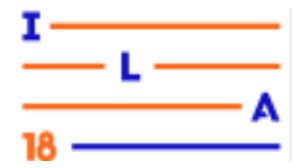

\title{
AVALIANDO A ATRATIVIDADE DE UM PRODUTO INTERATIVO, ALÉM DA USABILIDADE
}

\section{EVALUATING THE ATTRACTIVENESS OF INTERACTIVE PRODUCT, BEYOND USABILITY}

\author{
Filipe Landu Nzongo ${ }^{1}$, Bs Eng. de software \\ (1) Centro universitário de Faculdades de universitário - CUFMU \\ E-mail: filipelosoft@gmail.com
}

Palavras-chave: Avaliação, atratividade, AttrakDiff.

Está pesquisa teve como objetivo avaliar a percepção que os usuários têm num determinado produto interativo e a estética que o mesmo possui, levando em consideração as emoções que sentem ao utilizá-lo, como alegria ou entusiasmo, que irá influenciar a atratividade que atribuem a ele.

Key-words: Evaluation, attractiveness, AttrakDiff.

This research aimed to evaluate the perception that users have in a certain interactive product and the aesthetics that it has, taking into consideration the emotions they feel when using the product, such as joy $o$ $r$ enthusiasm, that will influence the attractiveness that they attribute to it.

\section{Introdução}

Nos últimos anos o termo "experiência do usuário" (UX) tornou-se uma buzzword no campo da interação humano-computador (IHC) e design de interação. Com surgimento de novas tecnologias e amadurecimento da mesma, nota-se uma grande necessidade de desenvolver produtos interativos que agregam valor a vida dos utilizadores e que não focam apenas na usabilidade, muitas empresas acreditam que a experiência do usuário está atrelada a facilidade de uso que o produto oferece ao usuário, a experiência do usuário é subjacente e muito diferente da experiência geral e para que ela aconteça depende não só da usabilidade, como também da percepção cognitiva da pessoa envolvida. A experiência do usuário (UX) pode ser entendida como uma extensão do conceito de usabilidade, sendo a usabilidade mais objetiva em relação à interação usuário e produto. A (UX) considera os aspectos da usabilidade, mas tem ênfase na análise da satisfação do usuário em relação ao produto. (ARAUJO, 2014). No universo da interação humano-computador, um conceito bastante comum é a usabilidade, focamos tanto nela que esquecemos outros aspectos importantes que enriquecem a experiência do usuário, definida por (PREECE et al. 2005, p. 35) como "o fator que assegura que os produtos são fáceis de usar, eficientes e agradáveis - da perspectiva do usuário". No entanto, sistemas de interfaces podem apresentar falhas que interferem na usabilidade e causam problemas na interação. Desta forma, para melhorar a qualidade, diferentes métodos e técnicas têm sido apresentados para avaliar e aprimorar as interfaces (por exemplo, CYBIS et al., 2010; PREECE et al., 2005; MORAES; SANTA-ROSA, 2008). Entre os principais procedimentos empregados em IHC, que procuram detectar possíveis falhas que prejudicam a interação, estão os testes de usabilidade (BERG; ULBRICHT, 2013). Tradicionalmente as avaliações em usabilidade tem foco no desempenho dos sistemas e desempenho de usuários por meio de medidas de eficiência e eficácia, mas não foca em outros aspectos igualmente importantes que necessitam ser levados em consideração. (PAIXÃ̃ WALDEILSON \& ZANDOMENEGHI ANA LÚCIA, 2018). Emoções que os usuários sentem ao utilizar um produto, como alegria ou entusiasmo, influenciam a atratividade que eles atribuem ao produto, entregar uma experiência propriamente dita não é fácil, devemos sempre levar em consideração o contexto em que os usuários estão inseridos e os aspectos que envolvem a experiência em si. Atratividade não é algo que eu já vi testado muito em equipes, embora seja bastante útil e surpreendentemente fácil de fazer. Na construção de um produto digital a atratividade não é apenas algo bom de ter, é essencial na maior parte do tempo.

Por tanto, se avaliar apenas o lado instrumental não poderá avaliar outros aspectos importantes que podem afetar positivamente tanto usabilidade quanto a interação usuário e produto, por isso é preciso reconhecer também o valor da percepção estética na 
Interaction Latin America

Rio de Janeiro, Brasil - 2018

http://ila.ixda.org/2018

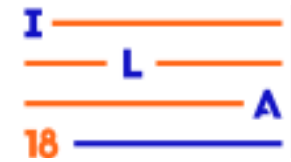

usabilidade, a fim desenvolver produtos interativos capazes de encantar. (HASSENZAHL, 2003) argumentou que o futuro da interação humanocomputador deve estar preocupado com os aspectos pragmáticos de produtos interativos (ou seja, apto para objetivos comportamentais) bem como também sobre os aspectos hedônicos, (isto é crescimento pessoal, aumento de conhecimentos e habilidades) identificação (auto expressão, a interação com outros relevantes) evocação (auto manutenção e memórias). Com vista em explorar melhor essas questões, o objetivo deste estudo tem como avaliar e explorar os aspectos relevantes que compõem um produto interativo, ao longo do artigo será abordado alguns assuntos que vão responder algumas perguntas sobre avaliação de interfaces, interação usuário e produto interativo, usabilidade, atratividade, perspectiva psicológica e perspectiva do design, quais aspectos importantes avaliar num produto interativo e como avalia-los. Deste modo, são realizadas algumas análises sobre as técnicas e métodos existentes.

\section{Fundamentos Teóricos}

A partir dessa etapa serão abordados alguns conceitos que vão nortear a nossa pesquisa e esclarecer alguns termos utilizados, assim como estabelecer uma comunicação consistente, com os leitores.

\subsection{Usabilidade}

Uma característica importante na interação humanocomputador, que está diretamente ligada às interfaces e a facilidade de manuseio que um produto oferece. A usabilidade é definida pelo ISO 9241:11 (ABNT NBR 9241:11, 2011) apresentado na figura 1. A usabilidade é uma exigência para o desempenho do usuário nas atividades que ele realiza por meio de um dispositivo interativo. Ela pode ser medida pela eficácia, eficiência e satisfação que determinados usuários devem alcançar em determinadas tarefas, como equipamento e ambiente.

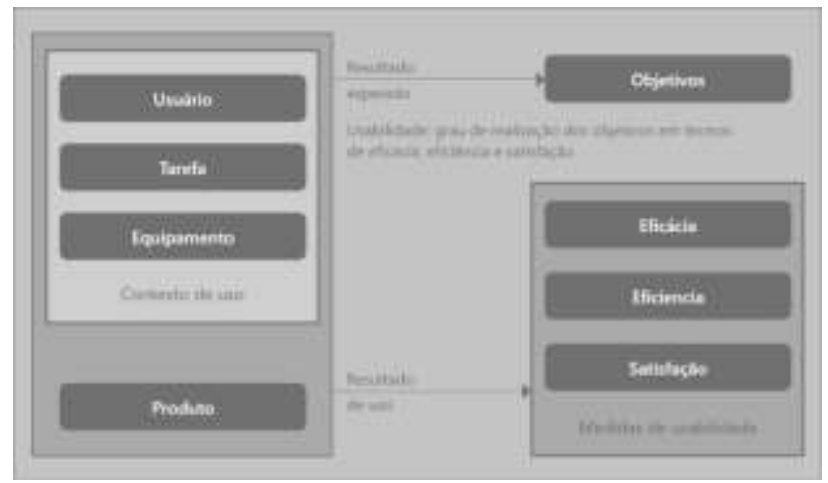

Figura 1 - Modelo conceitual da usabilidade segundo a norma ISSO 9241:11

Orientações sobre usabilidade é medida em termos de eficácia, eficiência e satisfação experimentadas interativo em um contexto de uso para obter objetivos específicos.

De acordo com este esquema acima, um primeiro grupo de especificações refere-se ao contexto de uso do software e visa esclarecer os projetistas sobre:

- As pessoas que usarão o sistema;

- As tarefas nas quais o sistema será empregado, incluindo seus projetos e objetivos;

- Os equipamentos nos quais o sistema será executado;

- Os ambientes físicos, tecnológico e organizacional nos quais as pessoas usarão o sistema.

No entanto, (CYBIS et al. 2010, p. 16) alerta que a usabilidade "não é uma qualidade intrínseca de um sistema, mas depende de um acordo entre as características de sua interface e as características de seus usuários ao buscarem determinados objetivos". Dessa forma, a usabilidade será a medida de qualidade que determinará o quanto a interação com as interfaces é satisfatória aos usuários. (PAIXÃO WALDEILSON \& ZANDOMENEGHI ANA LÚCIA, 2018).

\subsection{Interação Humano-Computador}

Corresponde ao "estudo da interação entre as pessoas (usuários) e hardware, software, sites e dispositivos móveis" (usability.gov, 2016). Para Cardoso et al. (2015, p. 5) "O IHC tem como objetivo o aprimoramento de sistemas para que forneçam usabilidade ao usuário", ou seja, permitir segurança e eficiência na realização das tarefas, e por um usuário quando este utiliza o produto 

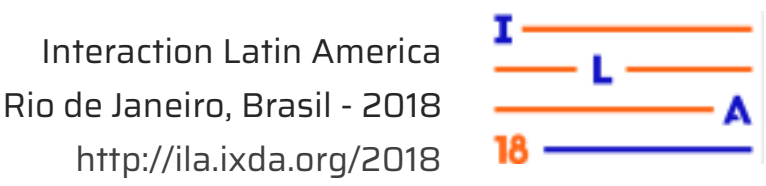

ainda propiciar prazer durante o uso. Parte da interação reside nas interfaces gráficas dos dispositivos, que provocam diferentes reações nos usuários. Segundo (CYBIS et al. 2010, p. 17), "Os programas de software e suas interfaces com o usuário constituem ferramentas cognitivas, capazes de modelar as representações, abstrair dados e produzir informações. Para projetar tais interfaces, os projetistas devem saber como é a estrutura dos processos cognitivos humanos" conjuntamente com as características das interfaces.

Para Padovan (2002) "Interação HumanoComputador é um campo de estudo multidisciplinar que tem como objetivo geral entender como e porque as pessoas utilizam ou não utilizam a tecnologia da informação" Hoje o termo aponta outros focos de interesse, "preocupando-se com todos os aspectos relacionados com a interação entre seres humanos e computadores", incluindo a configuração física dos equipamentos (não apenas computadores propriamente ditos) e o próprio ambiente informatizado. É importante lembrar que sistemas informatizados são quaisquer sistemas tecnológicos com algum tipo de processamento de informação e interação como smartphones, caixa eletrônica, robôs, chatbot ou ambientes interativos que contenham algum tipo de interface de controle.

\subsection{User Experience (Experiência de usuário)}

A experiência do usuário (UX) é um estranho fenômeno: prontamente adotadas pelo ser humano e pela comunidade de interação humano-computador (IHC), profissionais e pesquisadores, ao mesmo tempo é criticado repetidamente por ser um termo vago, evasivo e efêmero. O termo "experiência do usuário" está associado a uma grande variedade de significados (FORLIZZI; BATTARBEE, 2004), que vão desde a usabilidade tradicional para beleza, hedônica, afetiva ou aspectos experimentais do uso da tecnologia. A experiência do usuário vulgo (UX) é muitas das vezes compreendida de maneira ambígua, entretanto fez-se pesquisas para apresentar algumas definições de outros pesquisadores e profissionais do ramo da UX. Desta pesquisa foram encontradas várias definições que explicam a experiência de usuário, entre elas escolheu-se quatro que explicam de maneira coesa:

De acordo com o Norman (2018), o criador do termo UX explica que, a experiência do usuário engloba todos os aspectos da interação do usuário final com a empresa, seus serviços e produtos. (nngroup.com).
Segundo o Hessenzahl (2013), experiência do usuário não é sobre boas interfaces de design industrial multi-toque ou fantasia. É sobre transcender o material. Trata-se de criar uma experiência através de um dispositivo. (HASSENZAHL \& TRACTINSKY, 2006). Explicam que a experiência do usuário é uma consequência do estado interno de um usuário (predisposições, expetativas, necessidades, motivação, humor, etc.) as características do sistema projetado (por exemplo, complexidade, finalidade, usabilidade, funcionalidade, etc.) e o contexto ou o ambiente onde a interação ocorre (por exemplo, ambiente organizacional, social, intenção de uso, etc.) (User experience - A research agenda).

Laura Klein (2015) afirma que o design de experiência do usuário é o processo usado para determinar como será a experiência quando um usuário interage com seu produto, continuando nessa mesma linha de pensamento, ela acredita que a experiência do usuário sempre acontece. Seja intencional ou não, alguém toma as decisões sobre como o humano e o produto irão interagir. $\mathrm{O}$ bom design de experiência do usuário acontece quando essas decisões de uma forma atendem e compreendem as necessidades de nossos usuários e de nosso negócio. (usertesting.com, 2015). Hekkert (2006) define a experiência do usuário como todo o conjunto de afetos que é suscitado pela interação entre um usuário e um produto, incluindo o grau em que todos os nossos sentidos são gratificados (experiência estética), os significados que atribuímos ao produto (experiência de vida), e os sentimentos e emoções que são provocadas ao utiliza-la (experiência emocional).

\section{O que é a estética}

A estética é o estudo filosófico da beleza e do sabor. O termo deriva da palavra grega "aisthetikos", que significa "percepção sensorial", está relacionada ao estudo dos valores sensoriais. No design, a estética refere-se à atratividade visual de um produto. Estudos comprovaram que criar uma boa estética em um produto leva a uma melhor usabilidade e experiência do usuário. No campo da experiência do usuário (UX) e design de interação, a estética é importante porque afeta a (UX) de um produto de várias maneiras. Em primeiro lugar, cria um viés de atratividade, que se resume ao fato de que somos atraídos por coisas belas. Quando os usuários acessam um site ou testam um novo aplicativo, tomam decisões rápidas sobre continuar ou não a usá-lo. Grande parte dessa decisão depende do apelo 
estético do design. Em segundo lugar, uma boa estética ajuda a tornar os usuários mais tolerantes a problemas de usabilidade. Estudos descobriram que sites visualmente atraentes são classificados como mais úteis do que realmente são, porque sua atratividade provoca emoções agradáveis nos usuários. Ao projetar com o propósito de aumentar o valor estético, uma consideração em particular é essencial - a noção de que a beleza não é apenas objetiva e universal (como argumentou o filósofo alemão do período iluminista, Immanuel Kant), mas que tem um lado subjetivo também. O histórico cultural, a educação ou a classe de um usuário podem influenciar seus julgamentos de valor estético. Os designers precisam entender esses aspectos para combiná-los com o design apropriado. Assim, como a estética envolve múltiplas dimensões da composição do público-alvo, exige pesquisas em diversas áreas relevantes para a distribuição de um produto, incluindo considerações de mercado externo.

\subsection{O poder da estética}

A estética é um atributo que desempenha um importante papel para motivar uma pessoa a usar uma interface ou um produto. (HASSENZAHL, 2004) esclarece que as pessoas servem-se da bela estética de uma interface, com qual se identificam, para comunicar aspectos de sua própria identidade. O encantamento estético é uma perspectiva da experiência que permanece estável apesar de eventuais problemas de uso, sendo mais ligado ao ego do que à obtenção de um objetivo. No entanto, Cybis et al. (2015, p. 24) faz-nos entender que o poder de encantar não será suficiente para motivar uma pessoa a usar um produto que não corresponda às suas expetativas mínimas de desempenho. Portanto Hassenzahl explica que aspecto estético pode de maneira subjetiva aumentar o prazer e a satisfação que o uso de um produto causa no usuário em uma determinada situação.

HASSENZAHL (2005) Ressalta que a percepção de um produto pelo o usuário tem uma perspectiva pragmática, ligada à maneira como ele percebe seu desempenho, e uma hedônica, ligada aos sentimentos de identificação, de estimulação e de evocação que $\mathrm{o}$ produto $\mathrm{o}$ produto provoca no usuário. Estas percepções variam de usuário para usuário em função das expetativas e das experiências com outros produtos. Isso explica por que, com tempo um mesmo usuário pode ver o produto de maneira diferente, e realça o aspecto subjetivo da experiência. O filósofo Immanuel Kant afirmou que juízos acerca de um gosto estão ligados a um desejo e produzem um sentimento de agradável que não é desinteressado, pois ele engendra o desejo de possuir o objeto ou de usufrui-lo. Então podemos dizer que os juízos acerca da beleza são baseados em sentimentos agradáveis, porem se distinguem daqueles sentimentos agradáveis que possuem alguma relação de desejo ou instrumental com o objeto qualificado belo. Entretanto os designers de produtos empregam conhecimento estético, habilidade e ferramentas para gerenciar as percepções do usuário com intenção de influencialo. Na literatura do design a estética é um conceito bastante complexo que envolve muitos fatores visuais diferentes que vão desde a hierarquia, composição visual, combinação de cores, harmonia, tipografia, entre outros. A estética desempenha um papel importante no design e na formação da aparência estética de um produto, que por sua vez influenciará a decisão de compra de um cliente.

\section{4. $O$ poder da atratividade na IHC}

A importância da atratividade ou estética visual para o campo da IHC pode ser discutida de várias perspectivas. Aqui eu apresento duas dessas perspectivas - a perspectiva do design e a perspectiva psicológica. Embora essas perspectivas não devam ser exaustivas, acredito que, juntas, elas cobrem a grande parte dos argumentos para a inclusão da estética visual como um aspecto importante da prática, pesquisa e educação de IHC (TRACTINSKY \& HASSENZAHL, 2005). Embora estas sejam perspectivas distintas, elas podem se sobrepor em certos pontos. Finalmente, para alguns, pode parecer um tanto redundante submeter esses argumentos, já que eles ganharam aceitação considerável na comunidade de IHC nos últimos anos. Ainda assim, acredito que é importante apresentá-las de forma organizada para esclarecer meu ponto de vista e fornecer às pessoas da comunidade um conjunto de argumentos que podem ser usados para defender a estética visual antes de outros profissionais (por exemplo, engenheiros de software e hardware, gerentes de produto, etc.) (interaction-design.org, 2018).

\subsection{A Perspectiva do Design}

Apesar de ser uma das mais novas disciplinas do design, o desenvolvimento da tecnologia interativa tornou-se rapidamente uma das atividades do design mais salientes. A relevância mútua de IHC e Design 

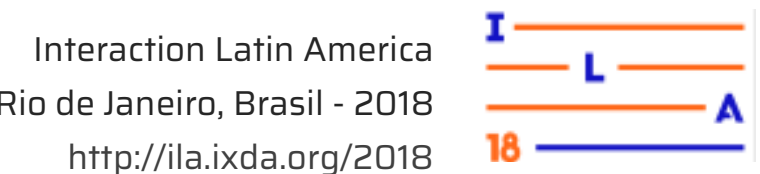

têm sido reconhecidos há muito tempo (WINOGRAD, 1996), mas quais são as implicações disso para a pesquisa, prática e educação em IHC? Aqui, gostaria de salientar duas dessas implicações. A primeira implicação é o reconhecimento de que a estética constitui uma parte importante e integrante de qualquer disciplina de design. (interactiondesign.org, 2018) A importância da estética aumenta conforme a interface entre o artefato e as pessoas afetadas (por exemplo, em termos de saliência visual, duração da interação ou coabitação) se tornam mais abrangentes. A segunda implicação é que a estética visual está frequentemente relacionada a outros aspectos do design. Assim, não devemos nos preocupar apenas com a troca de qualidades estéticas e outras qualidades de sistemas interativos, devemos abraçar a estética como uma dimensão que aumenta outros aspectos do design e a experiência interativa em geral.

\subsection{A Perspectiva Psicológica}

Nos primórdios da disciplina da interação humanocomputador, pesquisadores e profissionais enfatizaram critérios relacionados à tarefa, como a facilidade de uso e eficiência como os objetivos finais do design interativo. Para eles a estética nunca foi algo tão relevante nos produtos interativos, de certa forma a estética foi considerada gratuita, na melhor das hipóteses, ou mesmo prejudicial (NORMAN, 1988). No entanto, com a evolução a tecnologia interativa tornou tão presente na vida cotidiana, fazendo-se presente em quase todos os aspectos dela, ficou claro que essa posição deveria ser reavaliada (NORMAN, 2002, HASSENZAHL, 2007). O surgimento da pesquisa sobre estética visual no campo da interação humano-computador (IHC) teve suas raízes no movimento da "psicologia positiva" (SELIGMAN \& CSIKSZENTMIHALYI, 2000) que pedia uma mudança para lidar com as forças humanas e o bem-estar, em vez de fraquezas e remédios. Este sentimento foi entusiasticamente abraçado no campo da IHC no contexto do estudo da experiência do usuário (HASSENZAHL \& TRACTINSKY, 2006; LAW AND SCHAIK, 2010). Numa perspectiva psicológica, para a importância do design estético. A ideia básica é que o design estético influencia positivamente os processos emocionais e cognitivos (NORMAN, 2004). Isso, por sua vez, melhora a experiência das pessoas com a tecnologia, sua avaliação e suas atitudes em relação a ela (LEDER et al., 2004). Por tanto o grau de beleza estética de uma coisa depende de sentimentos e é subjetivo. De acordo com a estética, a psicologia é o ponto-chave de como uma pessoa deve perceber algo e como uma imagem será posicionada na mente do usuário e como isso gerará uma experiência (TRANCTINSKY, 1997). A essência deste aspecto baseia-se em sentimentos que são considerados o principal fator sobre como uma pessoa deve aceitar algo positivo ou negativo, consequentemente, proporcional à experiência. (HASSENZAHL \& TRACTINSKY, 2006) argumentam que a estética psicológica originou-se do comportamento humano. Segundo os autores, os usuários que são expostos a um estímulo visual elevado, o prazer estético aumenta. Mas quando os mesmos usuários estão mentalmente sobrecarregados, a complexidade do estímulo aumenta, e o prazer estético é reduzido.

(JACOBSEN, 2006) sugeriu um framework para a psicologia da estética que consiste em sete aspectos diferentes: Diachronia, Ipsichronia, mente, corpo,

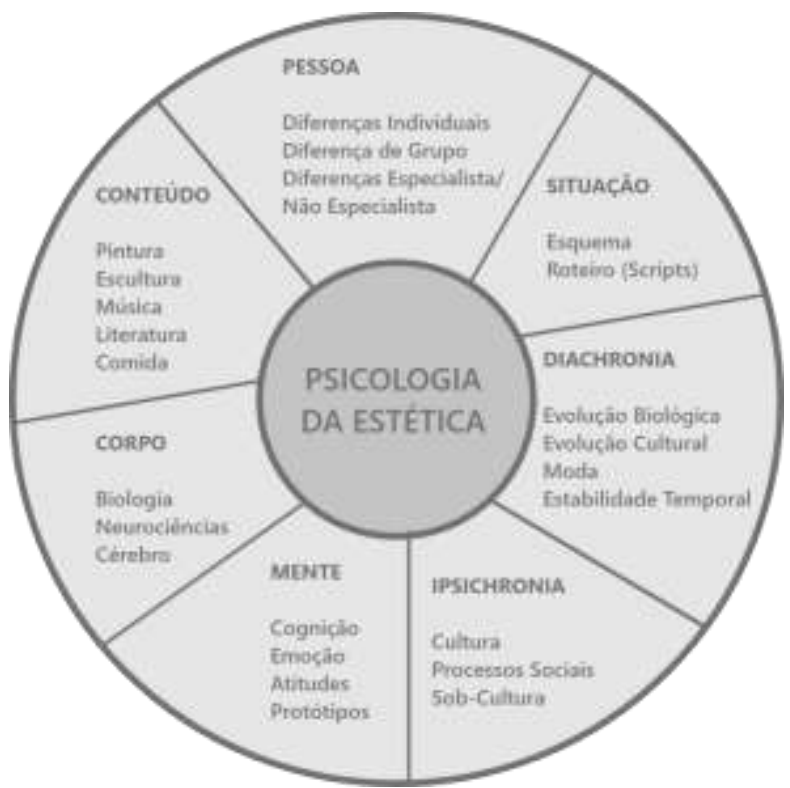

conteúdo, pessoa e situação:

Figura 2 - Framework para Psicologia da Estética, crédito Jacobsen. Versão portuguesa (Filipe Nzongo, 2018).

- Diachronia: As escolhas estéticas dependem do tempo;

- Ipsichronia: A vida cultural e social de uma pessoa afeta as opiniões estéticas da pessoa.

- Mente: Julgamentos estéticos influenciados pelo modelo mental do estímulo visual/emoções;

- Corpo: As atividades cerebrais podem ter um efeito nos processos de avaliação;

- Conteúdo: A avaliação estética de um estímulo pode ser influenciada pela conveniência de uso; 


\section{Interaction Latin America \\ Rio de Janeiro, Brasil - 2018 http://ila.ixda.org/2018}

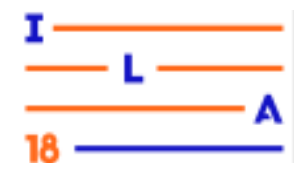

- Pessoa: Os antecedentes da pessoa podem desempenhar um papel para uma preferência estética;

- Situação: O tempo, o lugar e em geral as condições entorno são componentes que influenciam as escolhas estéticas.

Os aspectos acima mencionados da psicologia da estética não são mutuamente exclusivos, mas devem ser seguidos como guias enquanto determinam à estética (JACOBSEN et al., 2006)

\subsection{Qualidades Hedônicas e Pragmáticas}

HASSENZAHL e seus colegas (HASSENZAHL et al., 2000; HASSENZAHL, 2001, 2003) argumentaram que as qualidades percebidas de um produto podem ser divididos em dois, (MAHLKE, 2008) denominou essas qualidades em instrumentais e não instrumentais, essas duas qualidades diferentes remonta a (HASSENZAHL, 2002) que os chamavam de qualidades pragmáticos e hedônicos.

A qualidade pragmática refere-se a um julgamento de um potencial do produto para apoiar "metas" específicas (por exemplo, fazer um telefonema), primeiramente, a conquista de metas requer utilidade e usabilidade. Nesse sentido, um produto que permite a realização de metas eficazes e eficientes é percebido como pragmático (ou possui qualidade pragmática percebida). Em contraste a qualidade hedônica é um julgamento em relação ao potencial de um produto para apoiar o prazer no momento do uso isto é, o cumprimento dos chamados "objetivos" (por exemplo, ser admirado, causar emoção, materiais, forma e combinações de cores, etc.).

A qualidade hedônica subdivide-se em três partes (estimulação, identificação e evocação). De acordo com a noção de que a usabilidade ou qualidade pragmática está mais preocupada com a instrumentalidade de um produto, mas não é a fonte do prazer em si. São evidentes as correlações entre afeto positivo e percepções do produto, entretanto essa percepção influencia a emoção ou prazer que os usuários sentem ao utilizar um determinado produto. A qualidade hedônica sempre foi fortemente relacionada ao afeto positivo do que a qualidade pragmática. Por isso quando interagimos com um produto pela primeira vez somos atraídos pelo seu aspecto estético que de certa forma nos encanta, esse encontro puramente sensual pode acontecer por diferentes canais entre eles: visual, auditivo, olfativo ou táctil. Para o (MACDONALD, 2001; 2002), esse encontro é denominado como encontro sensorial, embora os aspectos estéticos não sejam explicitamente mencionados na estrutura, eles estão implicitamente incluídos no caráter do produto e nas qualidades do produto. Aspectos hedônicos englobam todos os aspectos estéticos e simbólicos. A estética desempenha um papel muito importante na avaliação de um produto, especialmente na primeira impressão, o ser humano não apenas "simplesmente" percebe as cores ou formas, como também faz análise estética de todos os produtos que interage com ele. As qualidades pragmáticas (instrumentais) desempenham um papel inferior nos encontros sensoriais.

Os encontros sensoriais podem ser comparáveis ao encontro de uma pessoa pela primeira vez. Através desse contato nós decidimos em segundos ou minutos se gostamos da pessoa, se nos daremos bem com ela e o que podemos esperar da pessoa. Criamos instantaneamente uma "personalidade" a partir de elementos que podemos perceber. No contexto da experiência do usuário o caráter do produto é construído a partir de qualidades pragmáticas e hedônicas, (JANLERT \& STOLTERMAN, 1997, p. 297), referem-se ao caráter como um "conjunto coerente de características e atributos que se aplicam tanto à aparência quanto ao comportamento, atravessando diferentes funções, situações e sistemas de valores estéticos técnicos e éticos, fornecendo suporte para antecipação, interpretação e interação". Quando os produtos podem provocar memórias, eles têm qualidades hedônicas, por exemplo, "souvenirs" são categorias de produtos que fornecem apenas valor hedônico, mantendo as lembranças de um lugar ou de um período da vida. Sendo assim um produto pode ser percebido como pragmático, porque ele fornece maneiras eficazes e eficientes de atingir objetivos comportamentais. Para, além disso, pode ser percebido como hedônico porque fornece estimulação por seu caráter desafiador e inovador, como também determina como os usuários percebem o produto a fim de estabelecer um contato sensorial agradável, antes mesmo que a interação real comece. 


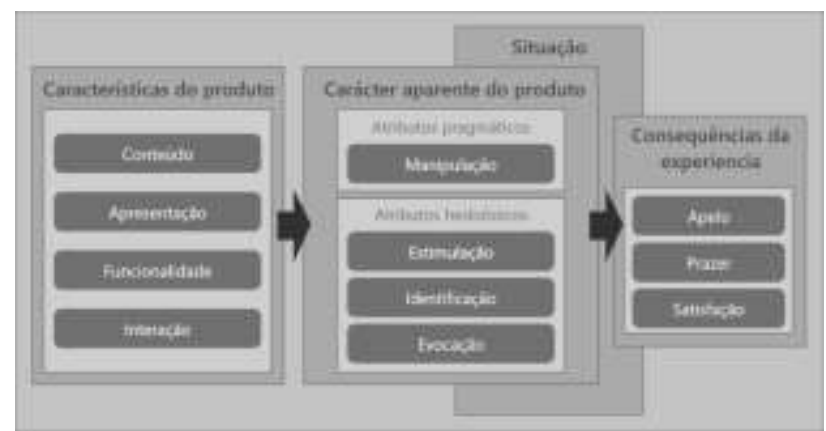

Figura 3 - Modelo de característica pragmáticas e hedônicas da experiência do usuário, crédito Hassenzahl (2005). Versão portuguesa (Filipe Nzongo, 2018).

Conforme ilustra o modelo da experiência do usuário de Hassenzahl, requisitos adicionais podem ser transmitidos aos projetistas, se referindo aos níveis de apelo (atração para o uso), prazer e satisfação que os usuários devem ser capazes de experimentar no uso continuado do produto.

\section{Escalas de Avaliação da UX}

Projetar um sistema ou produto com uma boa experiência do usuário é um dos principais objetivos de qualquer projeto digital. Para melhorar essa experiência durante o ciclo de desenvolvimento ou para garantir que o produto final tenha uma boa experiência de usuário, ainda é necessário saber como avaliá-lo de maneira confiável e válida. Questionários de autoavaliação estão entre os instrumentos mais utilizados para avaliar a experiência do usuário.

Com as escalas UX, você saberá rapidamente se o seu sistema é percebido pelos usuários como atrativo, eficaz, claro, confiável, desafiador ou inovador. As escalas de avaliação UX são derivadas de escalas de medição de usabilidade, foram desenvolvidos a partir do ano 1980. Os questionários padronizados consistem em um conjunto de perguntas apresentadas em uma ordem e formato predefinidos e seguem regras específicas para produzir métricas com base nas respostas dos participantes. Portanto para não confundir, as escalas de usabilidade focam mais nos aspectos pragmáticos da interação entre usuário e produto ou sistema. As escalas de medição da experiencia do usuário (UX) visam medir os aspectos pragmáticos e hedônicos da interação, sua concepção deve seguir um processo rigoroso para assegurar boas qualidades psicométricas, as escalas são relativamente curtas e fáceis de administrar, podem ser utilizados para análise rápida de dados.
Nesse artigo foi apresentado o modelo AttrakDiff do (HASSENZAHL et al., 2003) que é beseados na experiência do usuário. Os questionários de autoavaliação fazem parte dos instrumentos mais utilizados para avaliação da experiência do usuário, são utilizados em todos os ramos, entre eles (Desenvolvimento de vídeo jogos, aparelhos ligados à saúde, aplicativos moveis, sistemas multimodais, equipamentos de realidade virtual, inclusive em Sistema de Informação Geográfica). No meio academico esses metodos são inclusas nos estudos teoricos sobre UX, que aproveitam da natureza quantitativa e padronizada das escalas para explorar relações entre vários fatores da experiencia do usuário.

\section{O questionário AttrakDiff}

O questionário AttrakDiff, elaborado por (Hassenzahl, Burmester \& Koller, 2003) é uma das ferramentas de avaliação da experiência de usuário mais utilizada no meio acadêmico, permite avaliar as qualidades hedónicas e pragmáticas de sistemas interativos. É gerenciado pela sociedade Alemã User Interface Design $\mathrm{GmbH}$, que oferece acesso gratuito no seu site: http://attrakdiff.de/ inicialmente desenvolvido em alemão, recentemente traduzido e validado por (Filipe Nzongo, 2018) a fim de possibilitar estudos aprofundados na área de UX da comunidade do design da língua portuguesa.

AttrakDiff baseia-se no modelo teórico proposto por Hassenzahl, a ferramenta possui 28 itens repartidos em 4 subescalas (qualidade pragmática, qualidade hedônica-estimulação, qualidade hedônicaidentidade e atratividade global), segundo Hassenzahl os usuários percebem os produtos interativos de acordo com duas dimensões que são:

- As qualidades pragmáticas: A capacidade de apoiar realizações <do-goals> (Tarefas) Foco no produto (utilidade, usabilidade e realizações de tarefas). Um produto visto como tendo boas qualidades pragmáticas será estruturado, claro, controlável, eficiente, prático.

- As qualidades hedónicas: Capacidade de apoiar realizações <be-goals > Concentra-se a si mesmo (Por que possuímos e usamos um produto particular) um produto percebido como tendo boas qualidades hedónicas será original, criativo, cativante (vertente hedônica - estimulação) ou ainda 


\section{Interaction Latin America \\ Rio de Janeiro, Brasil - 2018 \\ http://ila.ixda.org/2018}

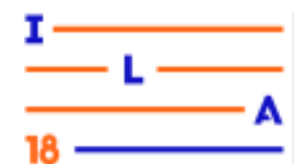

apresentável, profissional, bom gosto, que me aproxima dos outros (vertente hedónica - Identificação).

Essas duas dimensões (pragmáticas e hedônicas) influenciarão a percepção subjetiva da atratividade do produto ou sistema, que dará luz a outros comportamentos (por exemplo, aumento de uso) e emoções (por exemplo: felicidade ou frustração).

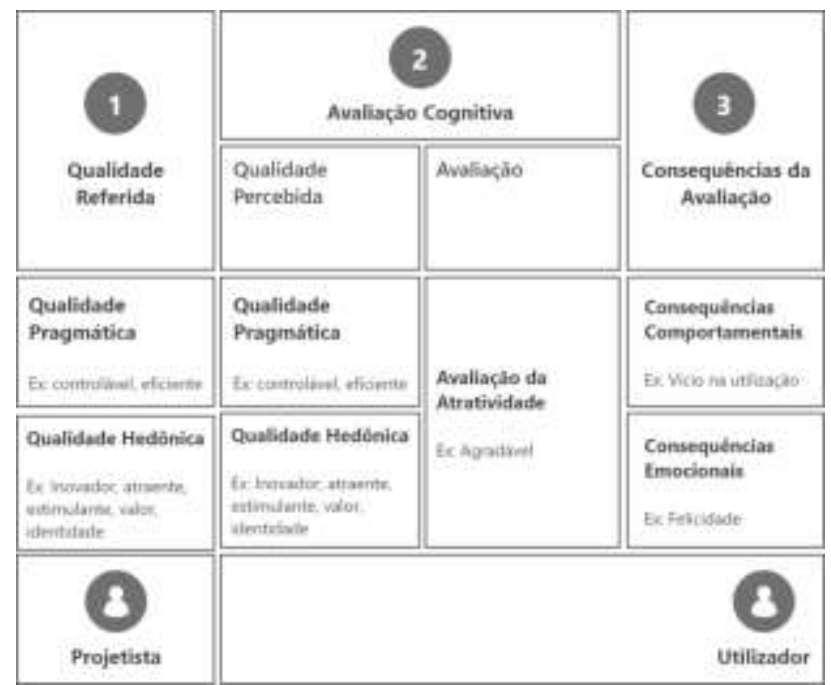

Figura 4 - Canvas do modelo teórico do Hassenzahl.

Versão portuguesa (Filipe Nzongo, 2018).

Como referida anteriormente, AttrakDiff possui 4 subescalas que permitem avaliar os sistemas de diferentes maneiras, elas são divididas da seguinte forma:

- $\quad$ Escala de Qualidade Pragmática (QP): descreve a usabilidade do produto e indica como o produto permite que os usuários atinjam suas metas;

- Escala de Qualidade Hedônica Estimulação (QH-S): indica quão bem o produto pode suportar a necessidade de estimulação;

- Escala de Qualidade Hedônica Identificação $(\mathrm{QH}-\mathrm{I})$ : indica em que medida $\mathrm{o}$ produto permite que $\mathrm{o}$ usuário se identifique com ele;

- Escala de Atratividade Global (ATT): descreve o valor global do produto com base na percepção das qualidades pragmáticas e hedônicas.

Os 28 itens estão na forma de diferenciadores semânticos (pares de palavras contrastantes) em sete pontos. Essas escalas não são classificadas textualmente, a ordem dos itens é padronizada.
Para serem avaliados por escalas Likert de sete pontos.

\begin{tabular}{|c|c|c|c|}
\hline \multicolumn{4}{|c|}{ AttrakDiff } \\
\hline Subescalas & \multicolumn{3}{|c|}{ Itens (em ordem de passação) } \\
\hline QP_1 & Humano & 0000000 & Técnico \\
\hline QHI__1 & Isola-me & 0000000 & Sociabiliza-me \\
\hline ATT_1 & Agradável & 0000000 & Desagradável \\
\hline QHS_1 & Original & 0000000 & Convencional \\
\hline QP_2 & Simples & 0000000 & Complicado \\
\hline QHI_2 & Profissional & 0000000 & Amador \\
\hline ATT_2 & Feio & 0000000 & Bonito \\
\hline QP_3 & Prático & 0000000 & Não é prático \\
\hline ATT_3 & Aprazível & 0000000 & Desaprazível \\
\hline QP_4 & Tedioso & 0000000 & Eficaz \\
\hline QHI 3 & Bom gosto & 0000000 & Mau gosto \\
\hline$Q P \_5$ & Previsível & 0000000 & Imprevisível \\
\hline QHI_4 & Baixa gama & 0000000 & Alta gama \\
\hline QHI_5 & Exclui-me & 0000000 & Integra-me \\
\hline QHI_6 & $\begin{array}{l}\text { Aproxima- } \\
\text { me dos } \\
\text { outros }\end{array}$ & 0000000 & $\begin{array}{l}\text { Separa-me } \\
\text { dos outros }\end{array}$ \\
\hline QHI_7 & $\begin{array}{l}\text { Não } \\
\text { apresentável }\end{array}$ & 0000000 & Apresentável \\
\hline ATT_4 & Repulsivo & 0000000 & Atraente \\
\hline QHS_2 & $\begin{array}{l}\text { Sem } \\
\text { imaginação }\end{array}$ & 0000000 & Criativo \\
\hline ATT_5 & Bom & 0000000 & Ruim \\
\hline QP_6 & Confuso & 0000000 & Claro \\
\hline ATT_6 & Repulsivo & 0000000 & Atrativo \\
\hline QHS_3 & Audacioso & 0000000 & Prudente \\
\hline QHS_4 & Inovador & 0000000 & Conservador \\
\hline QHS_5 & Chato & 0000000 & Cativante \\
\hline QHS_6 & $\begin{array}{l}\text { Pouco } \\
\text { exigente }\end{array}$ & 0000000 & Desafiador \\
\hline ATT_7 & Motivador & 0000000 & Desanimador \\
\hline QHS_7 & Novo & 0000000 & Comum \\
\hline QP_7 & Incontrolável & 0000000 & Manejável \\
\hline $\begin{array}{l}\text { Nota: Os ite } \\
\text { ATT_3, QHI } \\
\text { et QHS_7 e }\end{array}$ & $\begin{array}{l}\mathrm{QP} \text { 1, ATT_1 } \\
\mathrm{QP}_{-} \text {5, QHI_6 } \\
\text { o invertidos. }\end{array}$ & $\begin{array}{l}\text { QHS_1, QP_2, Q } \\
\text { ATT_5, QHS_3, }\end{array}$ & $\begin{array}{l}\text { II_, QP_3, } \\
\text { HS_4, ATT_7 }\end{array}$ \\
\hline
\end{tabular}

Tabela 1 - Versão portuguesa do questionário AttrakDiff (Filipe Nzongo, 2018).

\subsection{Passação e Pontuação}

Como qualquer outra escala de avaliação da experiência do usuário (UX) AttrakDiff é uma ferramenta auto administrada. Isso significa que os usuários podem preencher o questionário sozinho, tanto numa sala (depois de um teste de usuário, por exemplo) quanto on-line. Passação geralmente dura entre 5 e 10 minutos no máximo. Para quem tem pressa, existe uma versão resumida que contem apenas 10 itens.

\subsection{Tipo de avaliação}

A ferramenta AttrakDiff compõem três tipos de avaliação: 
- Avaliação única: adequada para uma avaliação única ou temporária de um produto ou sistema.

- Comparação antes e depois: Esse tipo de avaliação permite testar $\mathrm{o}$ produto duas vezes: antes e depois da implementação das alterações. Você terá um resumo detalhado dos efeitos das mudanças.

- Comparação de produtos A - Produto B: Este tipo de avaliação envolve dois produtos que são avaliados e comparados, você será capaz de ver como os usuários percebem produtos diferentes.

\subsection{Análise e interpretação de resultados}

A pontuação do AttrakDiff é relativamente fácil, para calcular a pontuação em primeiro lugar é necessário inverter certos itens, ou seja transformar a pontuação obtida pelo seu oposto. Esta etapa é necessária para evitar a tendência de aquiescência durante a passação, os itens não têm a mesma valência (às vezes a palavra à esquerda é negativa e às vezes é positiva). Antes de calcular a pontuação global, devemos nos garantir que os itens sejam pontuados na mesma direção, ou seja, os termos negativos estão à esquerda e os termos positivos à direita.

\begin{tabular}{|l|l|l|l|l|l|l|l|}
\hline Item normal & -3 & -2 & -1 & 0 & +1 & +2 & +3 \\
\hline Item invertido & +3 & +2 & +1 & 0 & -1 & +2 & +3 \\
\hline
\end{tabular}

Tabela 2 - A pontuação dos itens invertidos.

O próximo passo é calcular as médias e os desvios padrão para cada uma das quatro subescalas.

Para apresentar os resultados como um portfólio será é necessário calcular o intervalo de confiança. Análises estatísticas mais avançadas (cálculos de correlação ou regressão com outras variáveis) também podem ser realizadas, mas não serão usados nessa pesquisa.

\section{Apresentação dos Resultados}

A apresentação dos resultados após a passação pode ser feita de diferentes formas. Os projetistas da ferramenta (HASSENZAHL et al., 2003) propõem três formas principais.

\subsection{Diagrama de valores médios.}

Os valores médios das diferentes dimensões do
AttrakDiff são representados neste diagrama. As qualidades hedônicas de estimulação e identidade hedônica são diferenciadas e a atratividade global é apresentada. Os valores próximo da (zona entre 1 e 0) são padronizados: eles não são negativos, isso significa que o produto preenche seu objetivo sem ter impacto negativo. Todavia as melhorias são possíveis sobre esses aspectos para criar uma boa experiência do usuário ou atratividade muito positiva. Os valores fora desta zona neutra devem ser considerados como pontos positivo (de 1 a 3 ) ou negativo (de -1 a -3) do seu produto.

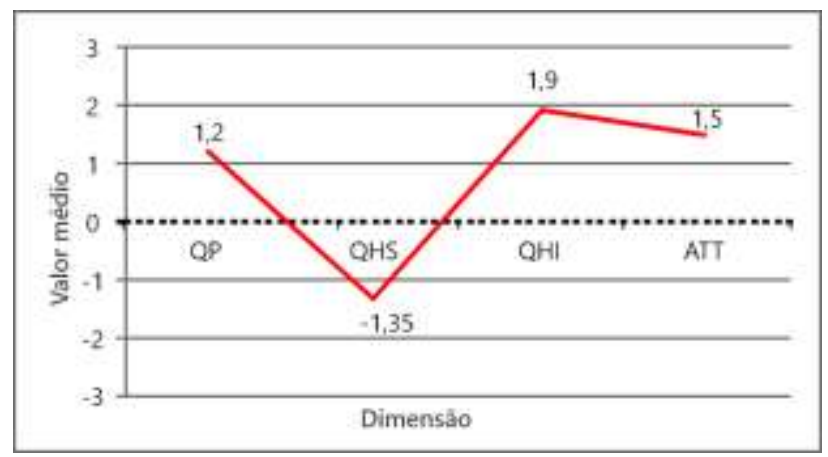

Figura 6 - Diagrama de valores médios

\subsection{Diagrama de pares de Palavras}

Este diagrama apresenta os valores médios de cada par de palavras. Os itens são reagrupados por subescalas e colocados em torno de uma sequência com o valor neutro 0 no centro, o que torna possível distinguir muito rapidamente quais aspectos são percebidos como negativos e quais aspectos são percebidos como positivos. Os valores extremos (entre -2 e -3 ou inversamente entre +2 e +3 ) são particularmente interessantes. Eles mostram quais dimensões são críticas ou, ao contrário, particularmente positivas, e exigem ações de melhoria nesses aspectos.

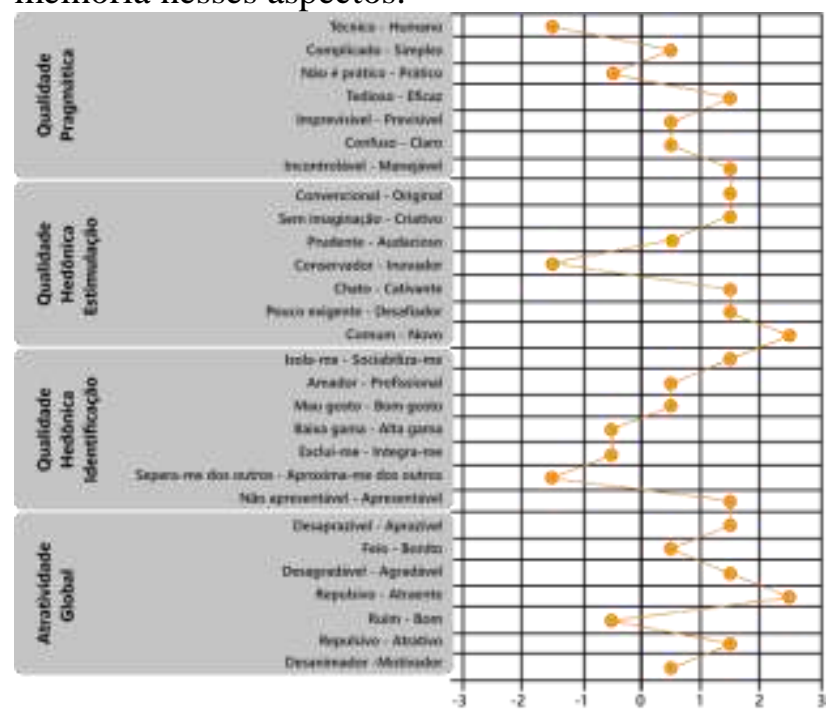



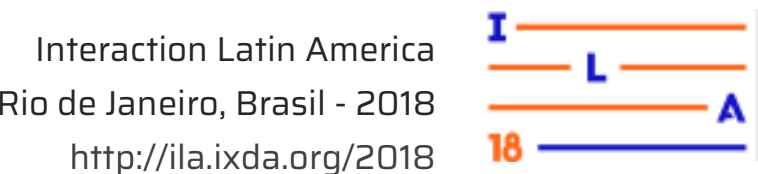

Figura 5 - Diagrama de pares de palavras adaptado AttrakDiff. Versão portuguesa (Filipe Nzongo, 2018).

\subsection{Portfólio de Resultados}

Nesta representação dos resultados, os valores médios obtidos nas escalas hedônicas são representados no eixo vertical (com valor abaixo o menor seja -3) e o valor médio na escala pragmática é representado no eixo horizontal (menor valor à esquerda). De acordo com as pontuações obtidas em ambas as dimensões, o produto ou sistema avaliado será posicionado em uma das zonas, definindo sua "personalidade" ou "orientação".

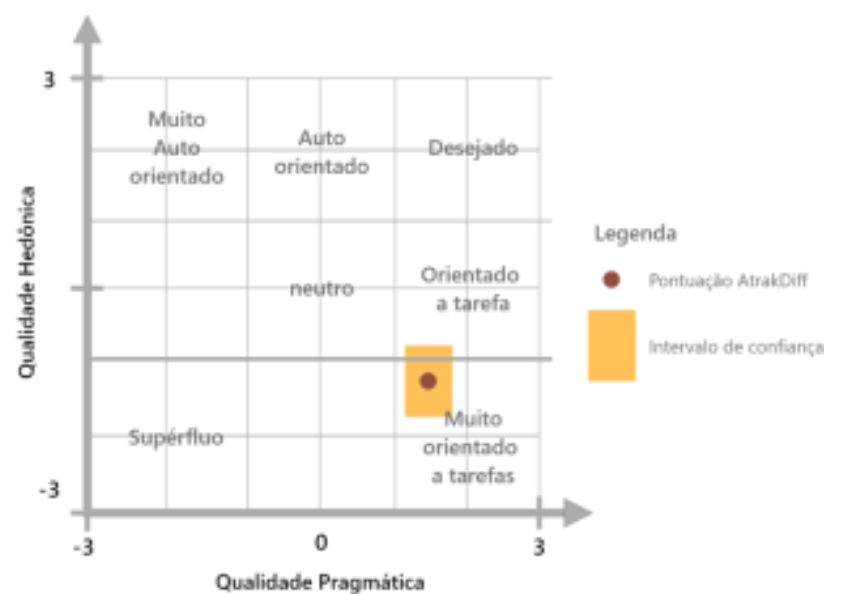

Figura 7 - Portfolio de resultado adaptado do AttrakDiff. Versão portuguesa (Filipe Nzongo, 2018).

Cada valor médio é cercado por um retângulo representando o intervalo de confiança do resultado. O retângulo de confiança mostra se os usuários fizeram uma avaliação consistente do produto ou se há uma grande variedade na avaliação. Quanto maior o intervalo de confiança, mais a avaliação variaram de acordo com os usuários. Assim, é mais difícil categorizar o produto em uma área específica. Um pequeno intervalo de confiança demostra uma avaliação menos variante, em função dos usuários e permite uma categorização consistente do produto avaliado pelos usuários mais do sistema.

\section{Exploração de resultado}

Avaliar a experiência do usuário não é um fim em si mesmo. $\mathrm{O}$ design centrado no usuário é um processo iterativo em que a avaliação é usada no design. Os resultados obtidos pelas escalas UX devem, portanto, ser usados para detectar os pontos fortes e fracos do sistema. Se os dados produzidos pelas escalas de UX não fornecem informações sobre os elementos que desencadeiam uma avaliação boa ou ruim, é possível, no entanto, conhecer a natureza disso, analisando em profundidade as pontuações para cada item da escala. Vamos tentar detectar quais dimensões do sistema já cumprem os objetivos de qualidade definidos e quais dimensões não atendem a esses critérios. O próximo passo será melhorar os aspectos mais fracos para garantir uma melhor experiência do usuário.

\section{Conselho prático}

- O AttrakDiff é uma ferramenta quantitativa, portanto, tente ter uma amostra de usuário razoável para uma entrega.

- Não modifique nenhum elemento do AttrakDiff (formulação de itens, número de itens, formato, ordem, etc.), caso contrário, as qualidades psicométricas do questionário serão deterioradas.

- Use a versão abreviada do AttrakDiff que possui 10 itens, se você não puder passar a escala completa.

- Adicione antes ou depois do AttrakDiff as questões sócio demográficas para cruzar os resultados de acordo com certas características da sua amostra. Os mais comuns são sexo, idade e senso de domínio da tecnologia.

\section{Apresentação dos resultados da pesquisa}

Ao longo dessa pesquisa investigamos o impacto da qualidade pragmática e hedônica na atratividade do aplicativo de mensageria instantânea denominado WhatsApp, avaliamos como os usuários percebem esse produto, que os apoia na comunicação no dia a dia.

\section{Participantes}

Para realizar da avaliação do produto mencionado anteriormente recrutou-se 12 pessoas com uma idade superior ou igual a 18 anos, residentes em diferentes regiões da cidade de São Paulo.

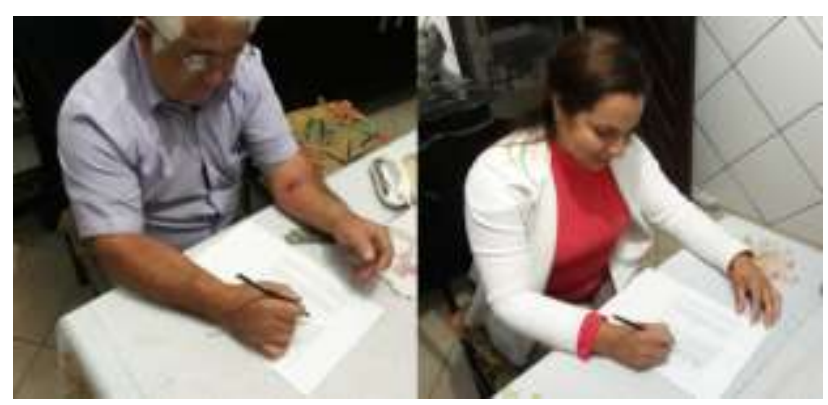


Interaction Latin America

Rio de Janeiro, Brasil - 2018

http://ila.ixda.org/2018

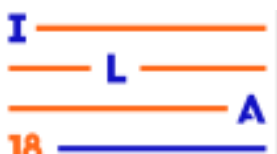

18
Figura 8 - Participante preenchendo o questionário AttrakDiff (fonte do autor)

\section{Instruções}

Primeiramente era explicado o objetivo da pesquisa para os participantes, eles foram informados que seriam fotografados, cada participante lia uma breve descrição da pesquisa. Após essa etapa lhes era apresentado o questionário AttrakDiff para preencherem onde os participantes forneciam suas avaliações levando em consideração seus contextos de uso do aplicativo.

\section{Resultados}

Apresentação dos resultados pode ser feita de várias formas, o criador do questionário propõe três maneiras diferentes. Nessa pesquisa apresentação dos resultados foi exibida através do diagrama de pares de palavras, após a avaliação do produto podemos observar a relação dos participantes com produto, podemos notar que existe uma grande diferença entre o gráfico lilás e laranja.

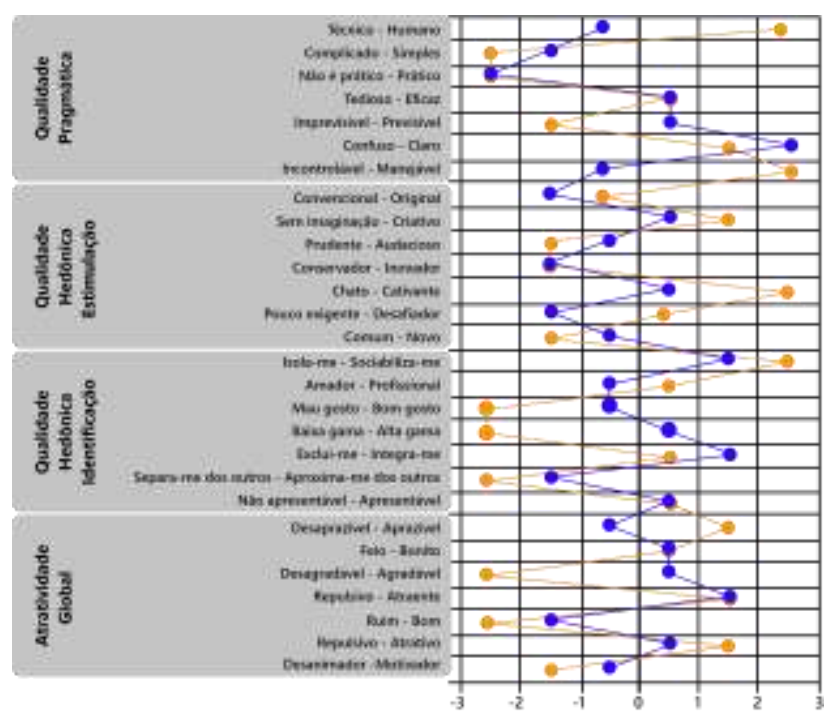

Figura 9 - Palavras de pares após avaliação (fonte do autor)

Nesta apresentação de portfólio de resultados, a qualidade hedônica distingue-se entre os aspectos de estimulação e identificação. Além disso, a classificação de atratividade é apresentada. Podemos observar que após avaliação do produto, o aplicativo mostra-se como controlável orientado a tarefa, neutro, desejável e auto-orientado. A avaliação também apresentou-nos a qualidade pragmática de 1,08 e hedónica de 1,04 de pontos.

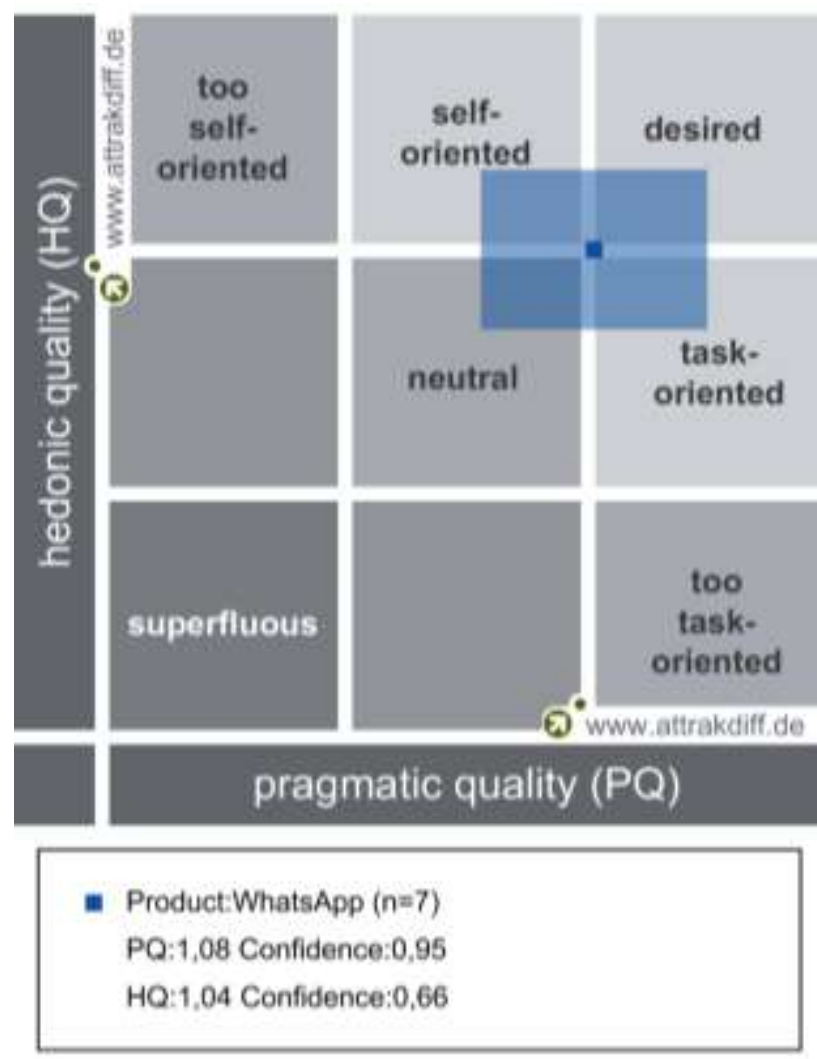

Figura 10 - Portfolio de resultado após avaliação (fonte do autor)

\section{Considerações Finais}

Está pesquisa objetivou avaliar a percepção que os usuários possuem sobre os produtos interativos, levando em consideração a estética que o mesmo possui como também as emoções que eles sentem ao utilizá-lo, que irá influenciar a atratividade que atribuem ao produto. Sendo assim acredita-se que as pessoas em geral gostam de experimentar algo bonito. $\mathrm{O}$ estudo de HASSENZAHL \& TRACTINSKY (2006) revelou que, se o usuário percebesse uma interface como "boa de aparência" seria fácil para ele usar e obter o que pretende, por tanto o grau de beleza estética de um produto depende de sentimentos e é subjetivo. Ao longo desta pesquisa questionou-se então o que é atratividade? Para responder a essa questão fez-se análise para entender as perspectivas proeminentes que envolvem essa questão. Como elas contribuem no campo da interação humano-computador (IHC) e para o nosso entendimento foram apresentados duas perspectivas entre elas a do design e psicológica. Através da perspectiva do design foi possível notar que a estética no design desempenha um papel de extrema importância e existe uma mutua relevância entre o campo da interação humano-computador e design, isso permitiu-nos entender que devemos 

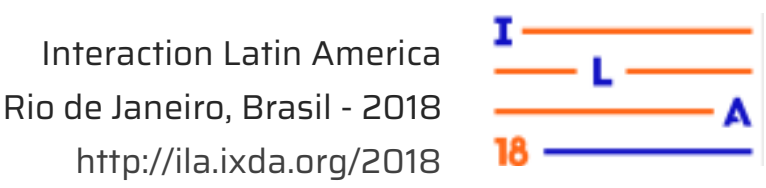

abraçar a estética como uma dimensão que aumenta outros aspectos do design e a experiência interativa em geral, a fim de criar contato sensorial atratativa entre o usuário e o produto. Deste modo acreditamos que numa perspectiva psicológica, o design estético influencia positivamente os processos emocionais e cognitivos dos usuários.

A segunda parte desse estudo apresenta-nos o framework da psicologia da estética desenvolvido por JACOBSEN (2006), observou-se que a avaliação estética de um produto depende de sete aspectos importantes que determinam à estética.

Entretanto HASSENZAHL defende que os usuários avaliam os produtos em duas dimensões pragmática e hedônica. MAHLKE denominou essas duas qualidades em instrumentais e não instrumentais.

Notou-se que as qualidades pragmáticas (instrumentais) focam apenas nas funcionalidades e na facilidade de uso que o produto possui em contrapartida as qualidades hedônicas que tem como foco os aspectos emocionais e cognitivos, ela referese aos aspectos como prazer, atratividade e satisfação. Percebemos a relevância da estética visual percebida e como ela influencia as reações emocionais dos usuários e consequências da experiência do usuário. Portanto a percepção de ambas as qualidades podem influenciar o terceiro componente da experiência do usuário, ou seja, as emoções que acompanham o processo de interação. Por exemplo, respostas lentas do sistema podem afetar a eficácia percebida e levar à impaciência ou mesmo à frustração e raiva. Em contraste um produto interativo com um design inovadora e simples, pode afetar a estética visual percebida e causar surpresa, curiosidade ou prazer. Para o HASSENZAHL (2007) Essas reações afetivas podem, em particular, desempenhar um papel importante na percepção dos aspectos estéticos, uma vez que a apreciação estética é frequentemente descrita como um processo parcialmente afetivo.

$\mathrm{Na}$ terceira parte deste trabalho foi apresentado o questionário AttrakDiff uma ferramenta importante para análise e avaliações dos aspectos estéticos de produtos interativos e não só, através dela podemos medir a atratividade de qualquer sistema interativo, combinando as qualidade hedônicas e pragmáticas do mesmo. Acredita-se que o estudo atingiu o objetivo proposto, que era investigar a conexão que há entre a atratividade e a usabilidade de produtos interativos.

Para finalizar ficou claro que as relações entre a estética visual percebida e os aspectos emocionais da experiência do usuário devem ser estudadas ainda mais, para entender como a estética pode ser importante para um produto interativo em comparação com a percepção de problemas de usabilidade e a consideração da estética visual em projetos de design de sistemas interativos. Apesar das dificuldades encontradas no momento do desenvolvimento desta pesquisa. Espera-se que os resultados aqui apresentados possam contribuir para ampliar essa discussão e ao mesmo tempo facilitar trabalhos futuros.

\section{Referências Bibliográficas}

THUERING, M.; MINGE, M. Hedonic and pragmatic halo effects at early stages of User Experience, International Journal of HumanComputer Studies, v.109, p. 13-25, janeiro 2018.

ZANDOMENEGHI, A.; PAIXÃO, W. Influência da estética visual na usabilidade e experiência do usuário em interfaces humano-computador uma revisão sistemática sobre instrumentos de avaliação. Jornal Ergodesign \& HCI, v.4, n. Especial, novembro 2016.

LIU, C.; LEE, C.; LEE, H. How do the aesthetics of hci design influence website credibiltiy: A Study of Online Banking Website Interfaces in Taiwan Journal of Internet Technology, v. 17, n. 3. 2016.

PHOTIADIS, T.; SOULELES, N. A Theoretical Model, including User-Experience, Aesthetics and Psychology, in the Design Process of 3D. Jornal of Virtual Worlds Research, v. 8, n. 1, p. 4-6, fevereiro 2015.

LALlEMAND, C.; GRONIER, G. Méthodes de design ux 30 méthodes fondamentales pour concevoir et évaluer les systèmes interactifs. 1 . Ed. Paris: Eyrolles, p. 370-380, 2015

JOKINEN, J. User psychology of emotional user experience. International Journal of HumanComputer Interaction, v. 30, n.4, abril, 2015.

HASSENZAHL, M.; DIEFENBACH, S.; GÖRITZ, A. Needs, affect, and interactive products - Facets of user experience. Interacting With Computers, The Interdiciplinary Jornal Of Human-Computer Interaction, v. 22, n.5, p. 357, abril 2010.

CYBIS, W. Ergonomia e usabilidade: conhecimentos, métodos e aplicações. 2 ed. São Paulo: Novatec, p. 422, 2010. 

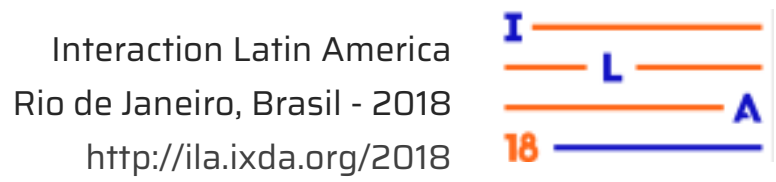

PREECE, J.; ROGERS, Y.; SHARP, H. Design de Interação: além da interação homemcomputador. 3 ed. Reimpressão Porto Alegre: Bookman, 2005.

MAHLKE, S. The study of visual aesthetics in human-computer interaction - Visual aesthetics and the user experience, 2008.

JACOBSEN, T. Bridging the arts and sciences: a framework for the psychology of aesthetics, v. 39, n. 2, maio 2006.

HASSENZAHL, M. The interplay of beauty, goodness, and usability in interactive products, p. 19, 319-349. Human-Computer Interaction, Darmstadt University of Technology, 2004.

LAVIE, T.; TRACTINSKY, N. Assessing dimensions of perceived visual aesthetics of web sites. International Journal Of Human-Computer Studies, v. 60, n. 3, p. 269-298, 2004.

HASSENZAHL, M. The thing and I: Understanding the relationship between user and product. 2003.

INTERACTION DESIGN FOUNDATION (IDF) What is aesthetics. Disponível em: <https://www.interaction-

design.org/literature/topics/aesthetics>. Acesso em 05 de mai. de 2018.

TRACTINSKY, N. Visual aesthetics in humancomputer interaction, 2011. Disponível em: $<$ https://www.interaction-

design.org/literature/book/the-encyclopedia-ofhuman-computer-interaction-2nd-ed/visualaesthetics> Acesso em 15 de abr. 2018.

CHAKRABORTY, A, 2017. The aestheticusability effect: why beautiful-looking products are preferred over usable-but-not-beautiful ones. Disponível em: $<$ https://medium.com/@coffeeandjunk/designpsychology-aesthetic-usability-effect494ed0f22571>. Acesso em: 20 jul.2018.

LANOUE, S, 2015. What is ux design? 15 user experience experts weigh in. Disponível em: $<$ https://www.usertesting.com/blog/2015/09/16/what -is-ux-design-15-user-experience-experts-weigh-in/> Acesso em: 12 de Abr. 2018

\section{Agradecimentos}

Quero agradecer essas pessoas que me ajudaram no processo de revisão. Andrei Gurgel, Daniel Furtado, Rodrigo Lemes, Cristiane Ellwanger e Ednora Augusta. 